Military Technical College

Cairo, Egypt

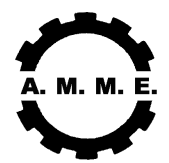

$12^{\text {th }}$ International Conference

on Applied Mechanics and

Mechanical Engineering (AMME)

\title{
RECONSTRUCTION OF DIESEL ENGINE CYLINDER PRESSURE USING ENGINE VIBRATION AND ACOUSTIC EMISSION
}

\author{
Badawi $^{*}$ A. B., A. Elmaihy ${ }^{* *}$, Samy ${ }^{* *}$ A. S., Shahin ${ }^{* * *}$, M. A. \\ and Mohamed ${ }^{* *}$ K. I.
}

\begin{abstract}
In this paper the diesel engine cylinder pressure is reconstructed in the crank angle domain using the measured engine vibration and acoustic emission. This technique depends on frequency analysis of engine vibration and acoustics. The frequency response functions (FRF's) are determined from the measured cylinder pressure, engine vibration and acoustic emission at specified engine speed and loads. The cylinder pressure is reconstructed from the measured engine vibration and acoustics at similar conditions by applying the inverse filtering technique using the already determined FRF's. The measured and reconstructed cylinder pressures are compared to each other for vibration and acoustics at different loads. Comparison between the reconstructed cylinder pressures from acoustic and vibration signals at the similar speeds and loads with the measured ones show good results as they are predicted. Slight differences in results for measured and reconstructed cylinder pressure for both vibration and acoustics is due to non-linearity of the engine system. The measured and reconstructed cylinder pressures from vibration signal are compared to that ones from acoustics for similar conditions and they have the same results.
\end{abstract}

\section{KEYWORDS}

Cylinder pressure, vibration, acoustics, frequency response function, fast Fourier transform and inverse filtering.

\footnotetext{
*PhD Postgraduate candidate, Dept. of Mech. Power and Energy, Military Technical College, Cairo, Egypt.

${ }_{* * * *}^{* *}$ Egyptian Armed Forces.

Assistant Prof., Faculty of Engineering, Modern University of Engineering and Technology, Cairo, Egypt
} 


\section{NOMENCLATURE}

\begin{tabular}{|c|c|}
\hline$A(t)$ & Acoustic signal in time domain \\
\hline $\mathrm{A}(\phi)$ & Acoustic signal in crank angle domain \\
\hline$A(\omega)$ & Acoustic signal in frequency domain \\
\hline $\mathrm{AE}$ & Acoustic emission \\
\hline BDC & Bottom dead centre \\
\hline c & Damping constant \\
\hline DFT & Discrete Fourier Transform \\
\hline $\mathrm{F}_{\mathrm{o}}$ & Force amplitude \\
\hline$F(t)$ & Force vector \\
\hline FFT & Fast Fourier Transform \\
\hline $\mathrm{fft}$ & MATLAB function for computing fast Fourier transform \\
\hline FRF & Frequency Response Function \\
\hline f & Frequency \\
\hline$f_{s}$ & Sampling frequency \\
\hline$H(\omega)$ & Frequency response function \\
\hline i & Sampling index \\
\hline ifft & MATLAB function for computing inverse fast Fourier transform. \\
\hline j & Imaginary unit \\
\hline $\mathrm{k}$ & Stiffness constant \\
\hline $\mathrm{m}$ & Mass \\
\hline $\mathrm{N}$ & Number of samples \\
\hline$P_{\text {meas }}$ & Measured cylinder pressure \\
\hline$P_{\text {recon }}$ & Reconstructed cylinder pressure \\
\hline$P(t)$ & Cylinder pressure signal in time domain \\
\hline $\mathrm{P}(\phi)$ & Cylinder pressure signal in crank angle domain \\
\hline$P(\omega)$ & Cylinder pressure signal in frequency domain \\
\hline RMS & Root mean square \\
\hline RMSE & Root mean square error \\
\hline TDC & Top dead centre \\
\hline $\mathrm{t}$ & Time \\
\hline $\mathrm{X}_{\mathrm{o}}$ & Response amplitude \\
\hline$X(t)$ & Fourier transform of a continuous signal \\
\hline$x$ & Displacement \\
\hline$x(t)$ & Response vector \\
\hline$\dot{x}$ & Velocity \\
\hline$\ddot{x}$ & Acceleration \\
\hline$X_{k}$ & Direct Fourier transform \\
\hline$x_{n}$ & Indirect Fourier transform \\
\hline $\mathrm{V}(\mathrm{t})$ & Vibration signal in time domain \\
\hline $\mathrm{V}(\phi)$ & Vibration signal in crank angle domain \\
\hline$V(\omega)$ & Vibration signal in frequency domain \\
\hline$\phi$ & Crank angle [degree] \\
\hline$\omega$ & Frequency \\
\hline
\end{tabular}




\section{INTRODUCTION}

Cylinder pressure provides comprehensive information about engine performance and operating conditions. It is directly related to heat analysis, pollutant information, vibration and mechanical events [1]. It can be used for heat transfer analysis [1], heat release analysis [2], engine control [3], and fault detection [4]. The traditional method for measuring the in-cylinder pressure is by fitting a pressure transducer in the combustion chamber through a hole in the engine cylinder head. This method is inconvenient in small engines with small space for fixation of the pressure transducer. Even in large engines with enough space it is too expensive to fix a pressure transducer in each cylinder in the engine. The pressure transducers have a limited lifetime in the combustion chamber environment of high heat and carbon deposits. Nowadays alternative possible method for reconstructing the in-cylinder pressure through easy-to-use and low cost transducers is looked for.

Brwon et. al. [3] and Citron et. al. [4] reconstructed cylinder pressure from crankshaft speed fluctuation. The conditions in the cylinder of an engine, the external load and the control parameters completely determine the flywheel angular velocity. If the conditions in the cylinders, the external load and the control parameters are known, then, at least in principle, the flywheel angular velocity can be calculated. The converse is only partly true. Given the angular velocity of the flywheel, it is only possible to determine some of the conditions in the cylinders. Therefore, the angular velocity of the flywheel is used for estimation of cylinder torque and in-cylinder pressure. Angular velocity fluctuation is measured with an interval timer and a magnetic sensor, by timing the flywheel gear teeth as they pass the sensor.

Zeng et. al. [1-2] used the reconstructed cylinder pressure for heat release and heat transfer analysis. The reconstruction of cylinder pressure is based on the concept of a dimensionless pressure curve in the frequency domain. It is shown that cylinder profiles acquired over a wide range of engine speeds and loads exhibit similarity. Hence, cylinder pressure traces collapse into a set of dimensionless curves within a narrow range after normalization in the frequency domain. The dimensionless pressure traces can be described by a curve-fit family, which can be used for reconstructing pressure diagrams back into time domain at any desired condition relative to known engine speed and load.

The relationship between the engine speed fluctuations and the pressure inside the cylinder was investigated by Moro et. al [5] using the FRF. The FRF is defined as the ratio between the FFT of the cylinder pressure and the FFT of the corresponding speed fluctuations. From many FRF values, each one corresponding to a different operating condition, FRF map was created for estimation of the in-cylinder pressure.

El-Ghamry et. al. [6] used acoustic emission (AE) for indirect measurement of the cylinder pressure from diesel engines. Raw $A E$ was utilized for modeling and reconstructing the pressure wave form in the time domain during expansion but not during compression due to lack of signal energy during compression. To overcome 
this problem the signal was divided into two sections representing the compression part of the signal and the fuel injection/expansion stroke. The compression part of the pressure signal was reconstructed by using polynomial fitting. An autoregressive technique was used during the injection/expansion stroke. The root mean square (RMS) acoustic emission signal is well correlated with the pressure signal in the time and frequency domain. The complex cepstrum analysis was then used to model the pressure signal for the complete combustion phase (compression, injection and expansion). The main advantage of using cepstral analysis is due to the utilization the frequency content of the RMS AE signal, which gives an advantage when the signal has lower energy content, during the compression process.

In this paper an indirect method to reconstruct in-cylinder pressure of single cylinder diesel engine is attempted. The method depends on the analysis of engine vibration and acoustic emission. The present technique depends on the relationship between the in-cylinder pressure, the engine acoustics and the engine surface vibrations. Firstly the FRF is considered as the ratio of the fast Fourier transform (FFT) of the cylinder pressure to FFT of the engine sound pressure. Secondly FRF is considered as the ratio of FFT of cylinder pressure to FFT of the engine surface acceleration. The frequency response functions are determined from the measured cylinder pressure, engine surface acceleration and engine sound pressure at specified engine speed and loads as signatures. Assuming that the engine is a linear system, the cylinder pressure is reconstructed from the measured engine vibration and acoustics for similar conditions by applying the inverse filtering technique to the FRF signatures.

\section{FREQUENCY RESPONSE FUNCTION}

The frequency response function FRF relates the output (displacement, velocity or acceleration) per unit of input (excitation force) at each frequency [7]. For an engine which is modeled as a linear single degree of freedom system the equation of motion is given by:

$$
m \ddot{x}+c \dot{x}+k x=F(t)
$$

The steady state solution is obtained by assuming that the excitation force $F(t)$ in Eq. (1) is a phasor described by:

$$
F(t)=F_{\circ} e^{j \omega t}
$$

where $F_{\circ}$ is the force amplitude.

According to[7-9], the response phaser is assumed to have the same frequency $\omega$ so that: 


$$
x(t)=X_{\circ} e^{j \omega t}
$$

where $X_{\circ}$ is the response amplitude. Substitution of Eq. (2) and (3) into (1) gives:

$$
\frac{X_{\circ}}{F_{\circ}}=\frac{1}{k-m \omega^{2}+j c \omega}=H(\omega)
$$

\section{DISCRETE FOURIER TRANSFORM}

According to Ziemer et. al. [10], the Fourier transform of a continuous signal, $x(t)$ is:

$$
X(f)=\int_{-\infty}^{\infty} x(t) e^{-j 2 \pi f t} d t
$$

The discrete Fourier Transform (DFT) is described as a double sampled version of the continuous-time Fourier transform (i.e., sampled in both time and frequency). The DFT pair is:

$$
X_{k}=\sum_{n=0}^{N-1} x_{n} e^{-j 2 \pi k n / N} \quad, \mathrm{k}=1,2, \ldots \ldots \ldots, \mathrm{N} .
$$

For the direct transform, and

$$
x_{n}=\frac{1}{N} \sum_{k=0}^{N-1} X_{k} e^{j 2 \pi k n / N}, \mathrm{n}=1,2, \ldots \ldots \ldots, \mathrm{N} .
$$

for the inverse transform.

To derive the DFT from the continuous-time Fourier transform, the time-sampling interval $S$ taken as $T / N=\Delta t$, where $N$ is the total number of samples taken in a $T$ second interval (time window), and the frequency-sampling interval is taken as $1 / T$. Thus, both relationships imply periodicity: the first in frequency with period $f_{s}$ $=\mathrm{N} / \mathrm{T}=1 / \Delta \mathrm{t}$, and the second is in time with period $\mathrm{T}=\mathrm{N} \Delta \mathrm{t}=\mathrm{N} / \mathrm{f}_{\mathrm{s}}$. In terms of the sample number, the first is periodic in $\mathrm{k}$ with period $\mathrm{N}$, and the second is periodic in $\mathrm{n}$ with period $\mathrm{N}$.

Fast Fourier transform (FFT) is another version of discrete Fourier transform requires samples of power $2, \mathrm{~N}$ samples that accept $\log _{2}\left(\mathrm{~N}=2^{\log _{2} N}\right)$ calculations, The FFT must be computed at all $\mathrm{N}$ samples at once, while the DFT can be computed at just few samples of interest. There are many algorithms in different programming languages for computing the FFT. Here a MATLAB algorithm is used for computing the FFT. FFT algorithm is a function exists in the MATLAB package it is written in the 
command window as $\mathrm{fft}(\mathrm{x})$ and its inverse is ifft(x) where $\mathrm{x}$ is the time domain signal. The FFT is faster than the DFT and that can be proved by an example. Equation (6) shows that for 8 samples the DFT can be performed by $\mathrm{N}^{2}$ or 64 complex multiplications. That means for each $X_{k}$, there is a sum of eight complex products for $\mathrm{n}$ goes from 0 to 7 . On the other hand the number of complex multiplications by FFT is approximately $\frac{N}{2} \cdot \log _{2} N$. Therefore, the number of complex multiplications by FFT for 8 samples are 12 which is approximately 5 time less than that by DFT.

\section{TEST SETUP}

In the present paper tests have been carried out on a single cylinder direct injection diesel engine Deutz F1L-511 with $7.7 \mathrm{Kw}$ power at $1500 \mathrm{rpm}$. Appendix (A) shows the engine specifications. The engine load is measured by an ELZE/Herman hydraulic dynamometer of type AN5F. The measurement of engine speed and digital triggering of sampling are encountered by a shaft encoder of type GI 328r. The incylinder pressure is measured by a Kistler 601A piezoelectric pressure transducer. The engine vibration is measured by a Brüel \& Kjaer accelerometer of type 4367 which is fixed on the engine head cover. The engine noise is measured by a Brüel \& Kjaer microphone of type 4190 at a distance of 1 meter (according to SAE handbook [11]) from the right side of the engine. Brüel \& Kjaer conditioning amplifier of type 2626 and Kistler 5010B charge amplifier are used for conditioning of vibration and pressure signals respectively. A Brüel \& Kjaer 8 channel microphone power supply of type 5697 used for conditioning the acoustic signal.

A National Instrument PCI-MIO-16E-1 card and LabVIEW 7.1 software are used for data acquisition. A P-III Dell computer with $933 \mathrm{MHz}$ processor, $128 \mathrm{MB}$ RAM and 80 GB HD is used. The data is acquired at speed $700 \mathrm{rpm}$ at no load, $40 \%$ loadand full load with sampling frequency $8400 \mathrm{~Hz}$.

\section{EXPERIMENTAL RESULTS}

The cylinder pressure, engine vibration and acoustics are acquired at engine speed $700 \mathrm{rpm}$ and different loads: zero load, 40\% load and full load. The time domain signals are converted into crank angle domain by multiplying the time by $6 n$ where $n$ is engine speed. The measured engine acoustic signals in crank angle domain $A(\phi)$ are shown in subfigure (a) of Fig.1, Fig.2 and Fig. 3 for zero, $40 \%$ and full loads respectively. The measured engine vibration signals in crank angle domain $\mathrm{V}(\phi)$ are shown in subfigure (b) of Fig. (1), Fig.2 and Fig.3 for zero, $40 \%$ and full loads respectively. The measured engine cylinder pressure $P(\phi)$ signals and acoustic signals in crank angle domain are shown in subfigure (c) of Fig. (1), Fig.2 and Fig.3 
for zero, $40 \%$ and full loads respectively. The measured engine cylinder pressure signals and vibration signals in crank angle domain are shown in subfigure (d) of Fig.1, Fig. 2 and Fig. 3 for zero, $40 \%$ and full loads respectively. The exact speeds 700,700 and $711 \mathrm{rpm}$ correspond to zero, $40 \%$ and full loads respectively. All the acoustic and vibration signals at different loads are filtered by a bandpass filter 1000$3000 \mathrm{~Hz}$, which is the bandwidth that contains the combustion induced noise and vibration.

\section{CALCULATION OF FRF FROM THE MEASURED ENGINE SIGNALS}

The FFT is obtained for the filtered acoustic signals $A(t)$ and vibration signals $V(t)$ at the different loads. The FRF's are calculated from the measured in-cylinder pressure and the FFT of acoustic and vibration signals by the following formulae:

For acoustics:

$F R F=\frac{F F T(A(t))}{F F T(P(t))}$

For vibration;

$F R F=\frac{F F T(V(t))}{F F T(P(t))}$

Equations (8) and (9) can be rearranged in other forms as functions of frequency;

$$
\begin{aligned}
& H(\omega)=\frac{A(\omega)}{P(\omega)} \\
& H(\omega)=\frac{V(\omega)}{P(\omega)}
\end{aligned}
$$

Where $H(\omega)$ is the FRF, $A(\omega)$ is the FFT of the acoustic signal, V( $\omega)$ is the FFT of the vibration signal and $P(\omega)$ is the FFT of the pressure signal. The calculated FRF,s from the cylinder pressure signals and acoustic signals are shown in subfigure (e) of Fig. (1), Fig.(2) and Fig.(3) for zero, $40 \%$ and full loads respectively. The FRF,s which are calculated from the cylinder pressure signals and vibration signals are shown in subfigure (e) of Fig. (1), Fig.(2) and Fig.(3) for zero, $40 \%$ and full loads respectively. 

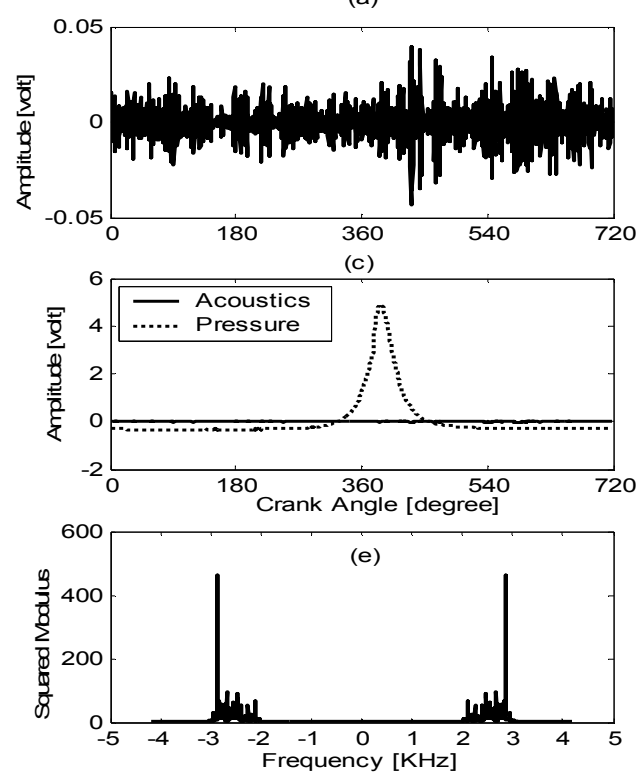

(b)
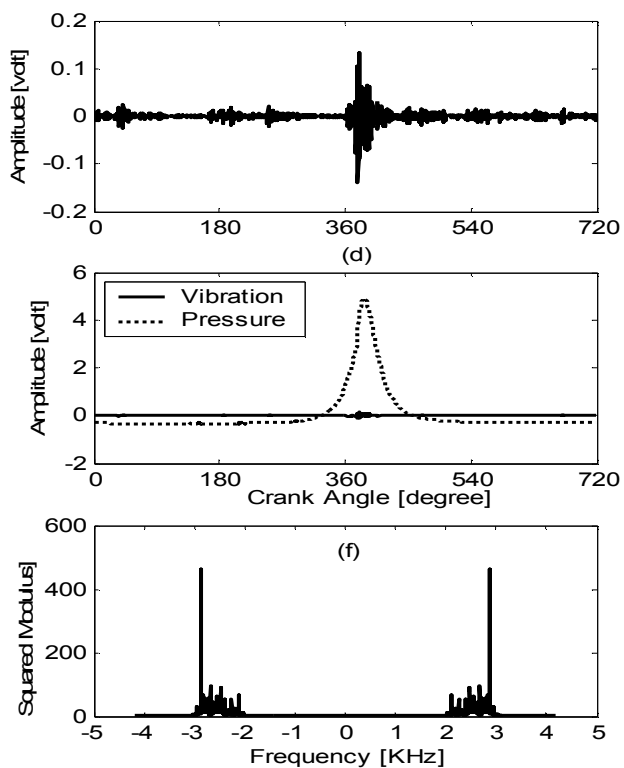

Fig.1.Measured engine cylinder pressure, vibration and acoustics, and calculated FRF at engine speed 700 rpm and zero load, (a) acoustic signal, (b) vibration signal, (c) cylinder pressure and acoustic signal, (d) cylinder pressure and vibration signal, (e) FRF from acoustic signal, (f) FRF from vibration signal.

(a)
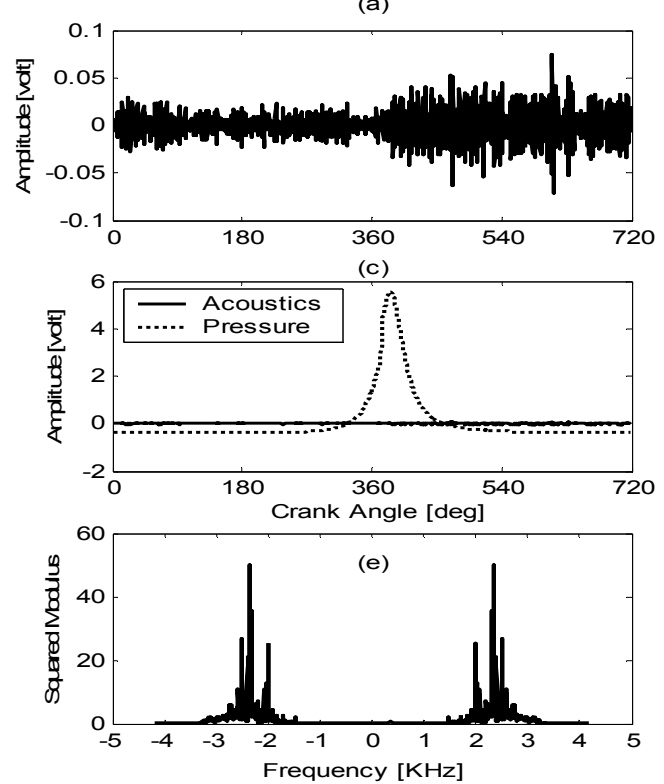

(b)
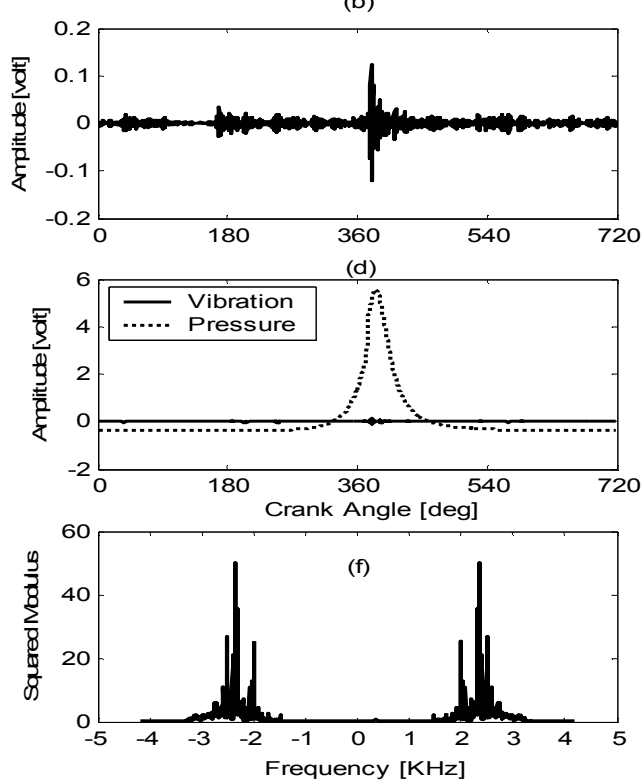

Fig.2. Measured engine cylinder pressure, vibration and acoustics, and calculated FRF at engine speed $700 \mathrm{rpm}$ and $40 \%$ load, (a) acoustic signal, (b) vibration signal (c) cylinder pressure and acoustic signal, (d) cylinder pressure and vibration signal, (e) FRF from acoustic signal, (f) FRF from vibration signal. 
(a)
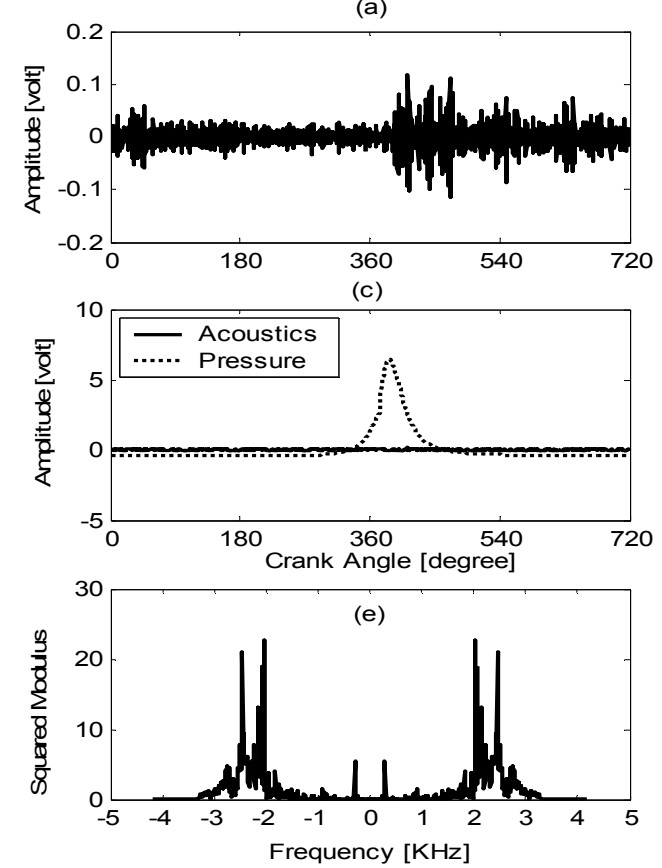

(b)
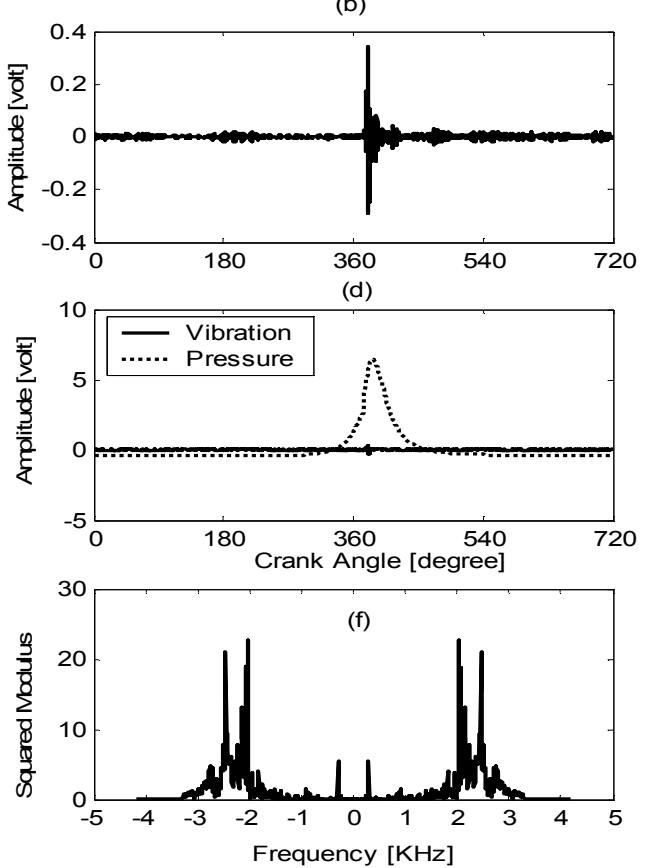

Fig.3. Measured engine cylinder pressure, vibration and acoustics, and calculated FRF at engine speed $700 \mathrm{rpm}$ and full load, (a) acoustic signal, (b) vibration signal, (c) cylinder pressure and acoustic signal, (d) cylinder pressure and vibration signal, (e) FRF from acoustic signal, (f) FRF from vibration signal.

\section{INVERSE FILTERING TECHNIQUE}

By inverse filtering is meant the inversing of the FRF $H(\omega)$. The inverse filter can be expressed as $H^{-1}(\omega)$ or $\frac{1}{H(\omega)}$. Inverse filtering technique has many applications in speech processing. It is used for estimation of pressure or airflow signal at the mouth during voicing. The application of inverse filtering for estimation of in-cylinder pressure is relatively new, although there are some authors utilized it according to ElGamry et. al. [6]. The reconstruction of cylinder pressure by inverse filtering is based on the processing of measured acoustic or acceleration signals and the in-cylinder pressure during combustion.

Equations (10) and (11) can be rewritten in forms of inverse filtering as follows:

$$
\begin{aligned}
& P(\omega)=A(\omega) H^{-1}(\omega) \\
& P(\omega)=V(\omega) H^{-1}(\omega)
\end{aligned}
$$


In equations (12) and (13) If the inverse filter $H^{-1}(\omega)$, acoustic response $A(\omega)$ and vibration response $\mathrm{V}(\omega)$ are known, the force response $\mathrm{P}(\omega)$ can be calculated.

Inverse filtering can be explained schematically as shown:

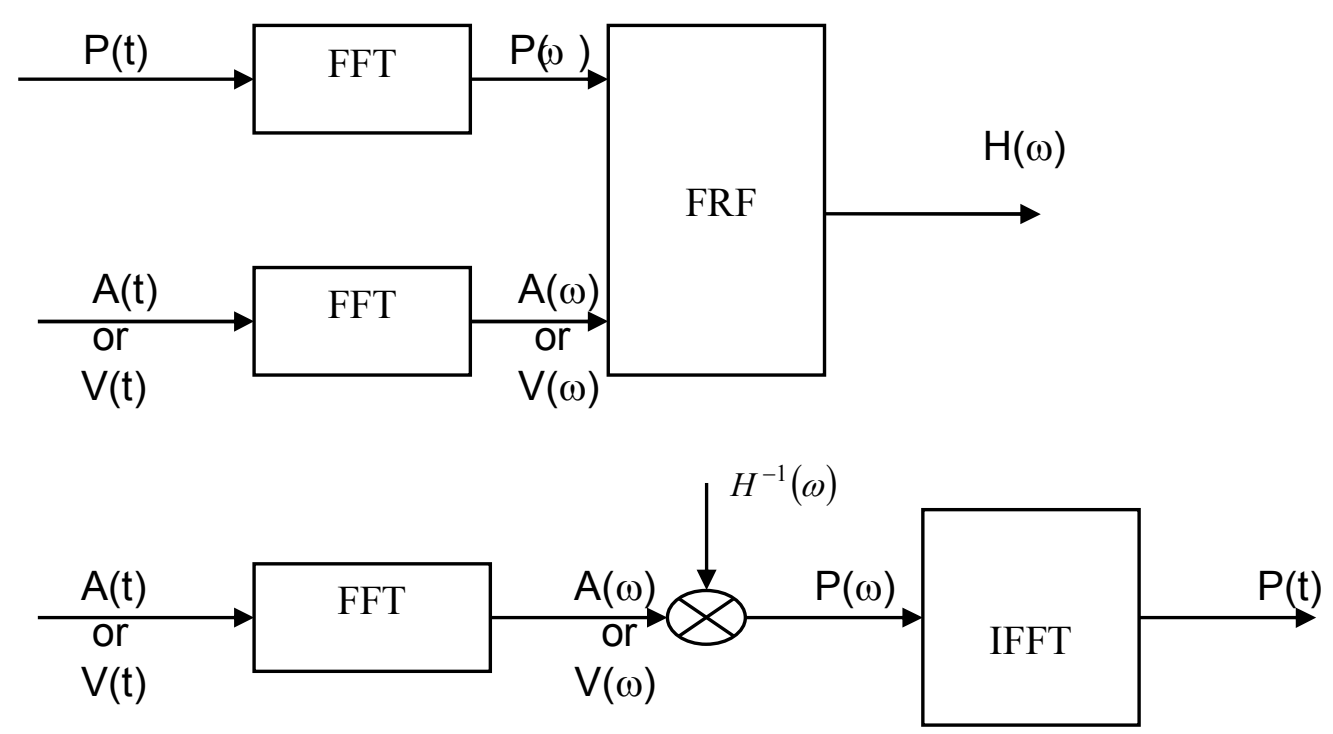

Fig.4. Schematic diagram shows the inverse filtering technique.

\section{RECONSTRUCTION OF CYLINDER PRESSURE}

The cylinder pressure is reconstructed from other measured acoustic and vibration signals at similar conditions alternative to that ones already used in calculation of FRF's (see Fig.5). The new acoustic and vibration signals which are acquired at zero, $40 \%$ and full loads correspond to speeds 700, 695 and 715 respectively. This acoustic and vibration signals are also filtered with the same bandpass filer 1000$3000 \mathrm{~Hz}$. The new reconstructed cylinder pressure signals from the new measured acoustic and vibration signals are calculated by applying the inverse filtering technique. The amplitude of the measured and reconstructed pressures is converted from volt to bar according to pressure transducer calibration curve that is shown in appendix (B). Figure.6.a, Fig.7.a and Fig.8.a show the new measured cylinder pressure and the reconstructed one from the new measured acoustic signal at zero load, $40 \%$ load and full load respectively. Figure.6.c, Fig.7.c and Fig.8.c show the new measured cylinder pressure and the reconstructed one from the new measured acoustic signal at zero load, $40 \%$ load and full load respectively at a range of $30^{\circ}$ before the TDC during compression stroke and $180^{\circ}$ after the TDC during expansion stroke. Figure.6.b, Fig.7.b and Fig.8.b show the new measured cylinder pressure and the reconstructed one from the new measured vibration signal at zero load, $40 \%$ load and full load respectively. Figure.6.d, Fig.7.d and Fig.8.d show the new measured cylinder pressure and the reconstructed one from the new measured vibration signal 
at zero load, $40 \%$ load and full load respectively at a range of $30^{\circ}$ before the TDC during compression stroke and $180^{\circ}$ after the TDC during expansion stroke. A comparison between the measured cylinder pressures, estimated ones from the new measured acoustic signals and reconstructed ones from the new measured vibration signals at zero load, $40 \%$ load and full load are shown in Fig.9.

Figure9.a, Fig.9.c and Fig.9.e show the new measured cylinder pressures, reconstructed ones from the acoustic signals and reconstructed ones from the vibration signals respectively. Figure.9.b, Fig.9.d and Fig.9.f show measured cylinder pressures, reconstructed ones from the acoustic signal and reconstructed ones from the vibration signal respectively at a range of $30^{\circ}$ before the TDC during compression stroke and $180^{\circ}$ after the TDC during expansion stroke of the engine cycle.

(a)

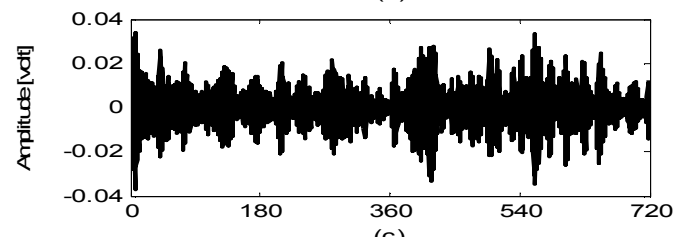

(c)

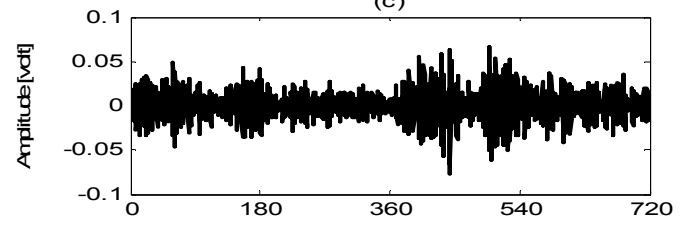

(e)

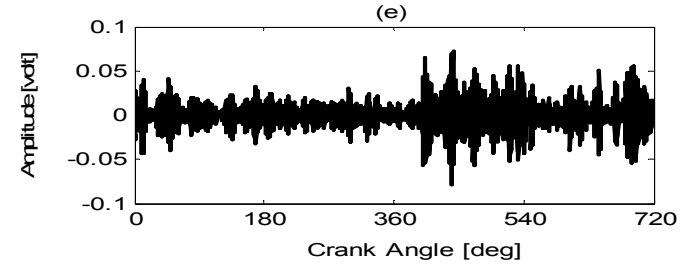

(b)
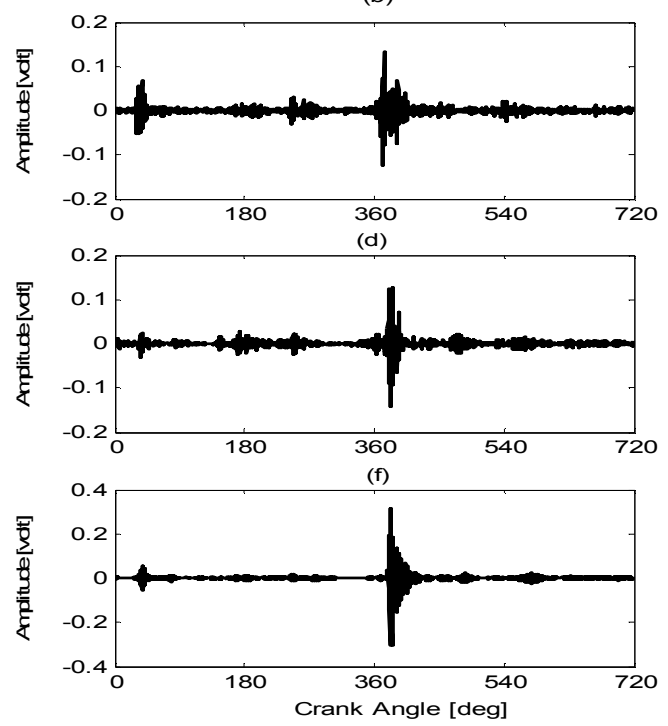

Fig.5. The another measured acoustic and vibration signals, (a) acoustic signal at speed $700 \mathrm{rpm}$ and zero load, (b) vibration signal at speed $700 \mathrm{rpm}$ and zero load, (c) acoustic signal at speed $695 \mathrm{rpm}$ and $40 \%$ load, (d) vibration signal at speed 695 rpm and $40 \%$ load, (e) acoustic signal at speed 715 rpm and full load, (f) vibration signal at speed $715 \mathrm{rpm}$ and full load.

\section{DISCUSSION OF RESULTS}

The root mean square error (RMSE) percentage is evaluated for the reconstructed cylinder pressure from acoustic and vibration signals as follows: 


$$
R M S E=\frac{\sqrt{\frac{1}{N} \sum_{i=1}^{N}\left(P_{\text {recon }}-P_{\text {meas }}\right)^{2}}}{\sum_{i=1}^{N} P_{\text {meas }}} \times 100
$$

The RMSE percentage between the measured and reconstructed cylinder pressure from the acoustic and vibration signals are shown in Table 1.

Table 1. Root mean square error (RMSE) percentage between the measured and reconstructed cylinder pressure at different loads

\begin{tabular}{|c|c|c|}
\hline \multirow{2}{*}{ Load } & \multicolumn{2}{|c|}{$\begin{array}{c}\text { Root Mean Square Error (RMSE) } \\
\text { Percentage }\end{array}$} \\
\cline { 2 - 3 } & Acoustics & Vibration \\
\hline Zero & $2.6 \%$ & $2.6 \%$ \\
\hline $40 \%$ & $2.4 \%$ & $2.4 \%$ \\
\hline Full & $3.8 \%$ & $3.8 \%$ \\
\hline
\end{tabular}

The measured cylinder pressure and the reconstructed one from acoustic and vibration signals at zero load, 40\% load and full load, as shown in Fig.6, Fig.7 and Fig.8, may be considered coincident. It is shown in Fig.6.a and Fig.6.c that the reconstructed cylinder pressure from acoustic signal at load zero is less than the measured one with an error of about 2.6\%. Similarly, Fig.6.b and Fig.6.d show that the reconstructed cylinder pressure from vibration signal at zero load is the same as that reconstructed from the acoustic signal with the same error $2.6 \%$.

Figure7.a and Fig.7.c show that the reconstructed cylinder pressure from acoustic signal at $40 \%$ load is less than the measured one with an error of about $2.4 \%$. Similarly, Fig.8.b and Fig.8.d show that the reconstructed cylinder pressure from vibration signal at zero load is the same as that reconstructed fro the acoustic signal with the same error $2.4 \%$.

The reconstructed cylinder pressure from acoustic signal at full load differs from the measured one with an error of about 3.8\%, see Fig.8.a and Fig.8.c. Similarly, Fig.8.b and Fig.8.d show that the reconstructed cylinder pressure from vibration signal at zero load is the same as that reconstructed fro the acoustic signal with the same error $3.8 \%$.

Figure.9.a and Fig.9.b show a comparison between the measured cylinder pressures at different loads, zero, $40 \%$ and full. The measured cylinder pressure increases with the increase of load at constant speed. The reconstructed cylinder pressure at $40 \%$ load is the greatest and that at full load is the smallest, and that at zero load is in between which is abnormal criteria. The reconstructed cylinder pressure from acoustic signal at $40 \%$ load is the greatest and that at zero load and full are the 
smallest and coincided, see Fig.9.c and Fig.9.d. The reconstructed cylinder pressure from vibration signal at $40 \%$ load is the greater at the curve beak and the smaller at the ends of the strokes than at zero and full loads which are coincident, see Fig.9.e and Fig.9.f. Also the coincident of full load and zero load, and increase of $40 \%$ load at the curve beak is abnormal. This abnormality may be due the linearity assumption of the engine vibrating system. In fact the engine system is nonlinear, because the inertia of the engine varies with the crank angle. Therefore, the validity of the assumption of linearity is limited for low speed engines. Also the assumption of single degree of freedom is limited for a single cylinder engine. The assumption of single degree of freedom is invalid for a multi-cylinder engine. The degree of freedom should be at least equal to the number of cylinders.
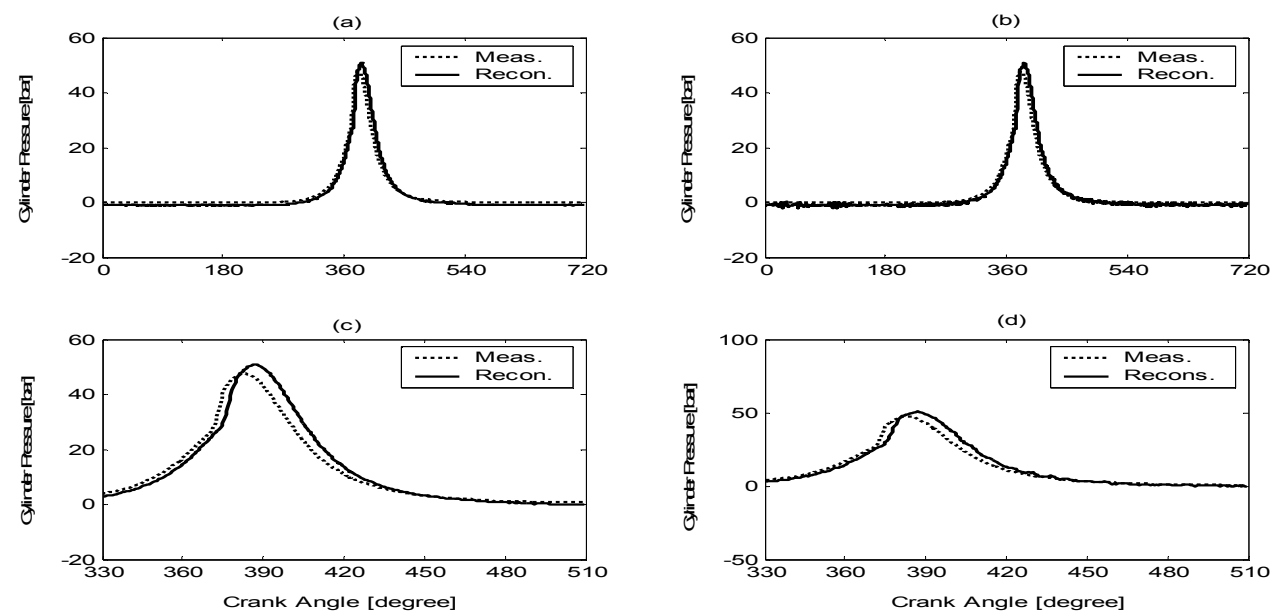

Fig.6. Measured and reconstructed engine cylinder pressure at zero load, (a) measured and reconstructed from acoustic signal, (b) measured and reconstructed from vibration signal, (c) and (d) zoomed figures for (a) and (b) respectively.
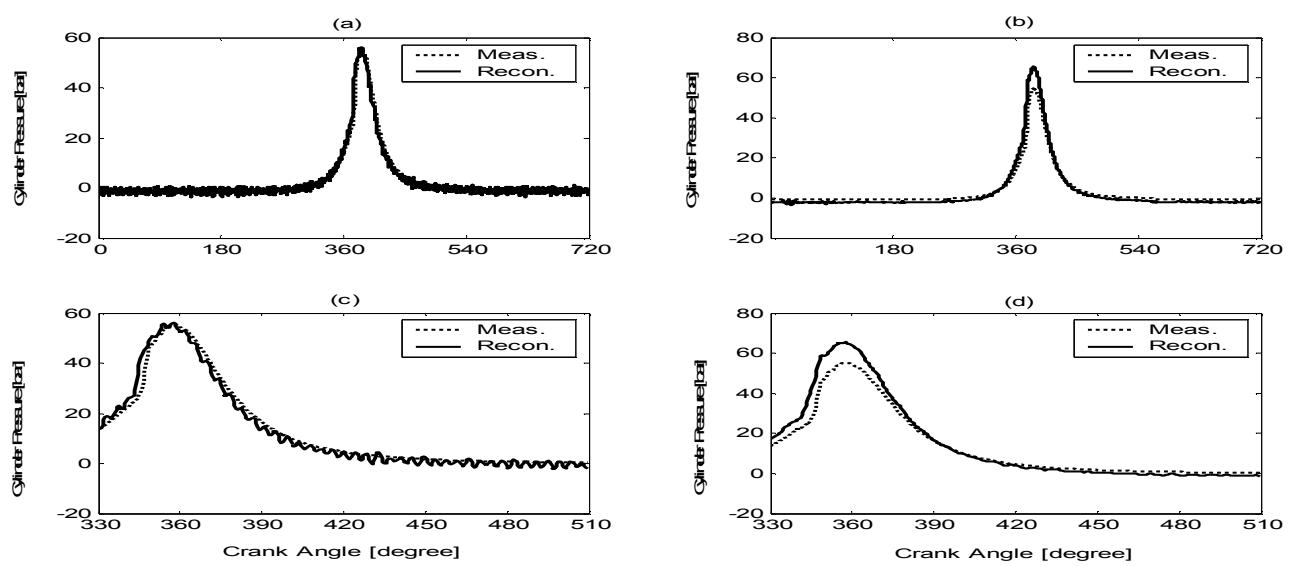

Fig.7. Measured and reconstructed engine cylinder pressure at $40 \%$ load, (a) measured and reconstructed from acoustic signal, (b) measured and reconstructed from vibration signal, (c) and (d) zoomed figures for (a) and (b) respectively. 
(a)

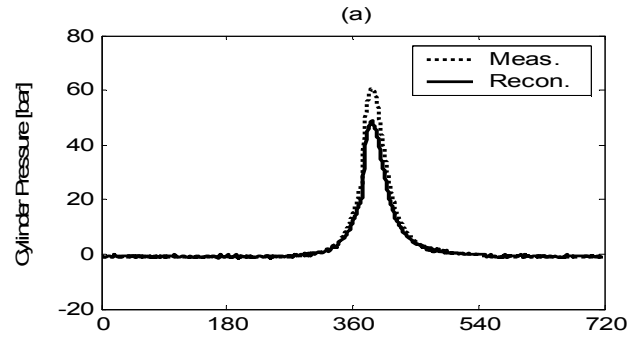

(c)

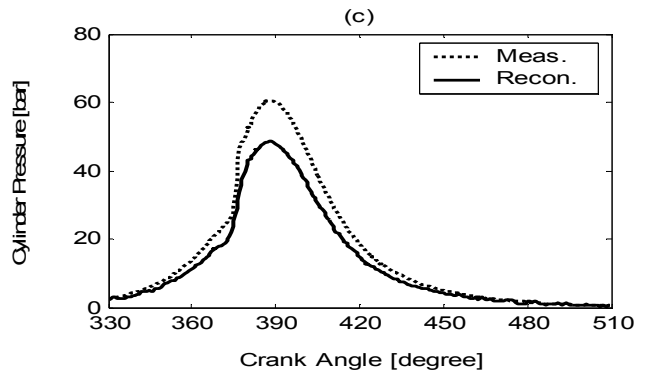

(b)

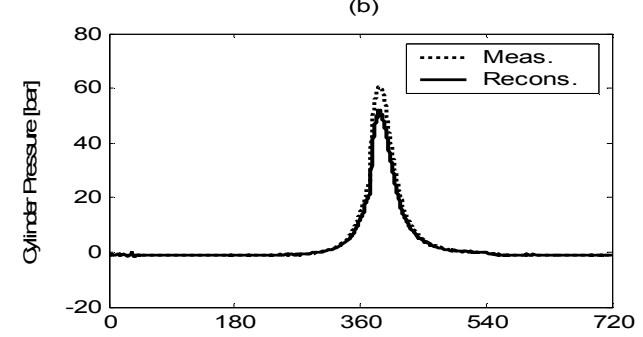

(d)

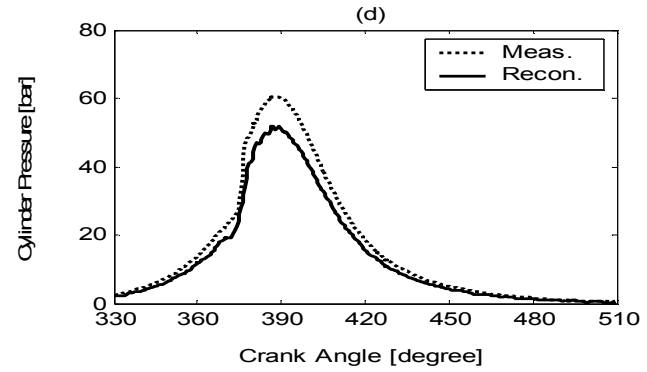

Fig.8. Measured and reconstructed engine cylinder pressure at full load, (a) measured and reconstructed from acoustic signal, (b) measured and reconstructed from vibration sigal, (c) and (d) zoomed figure for (a) and (b) respectively.

(a)
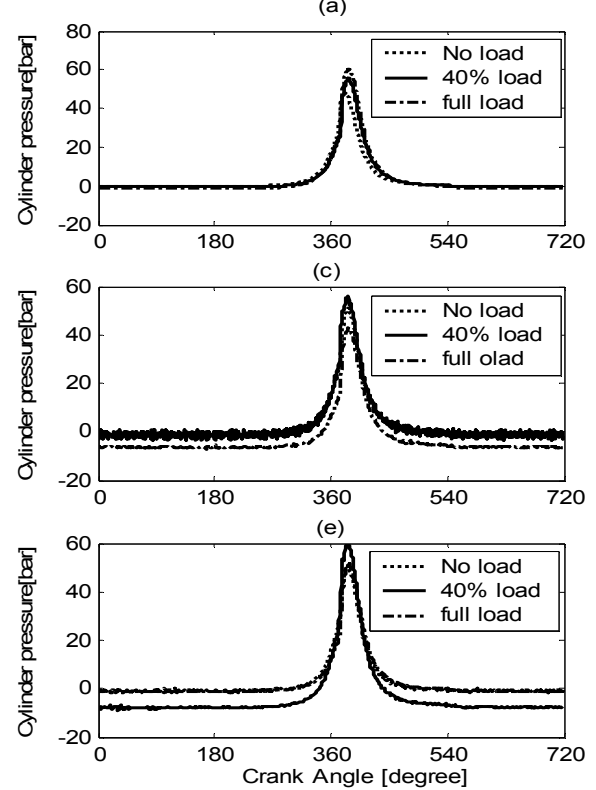

(b)

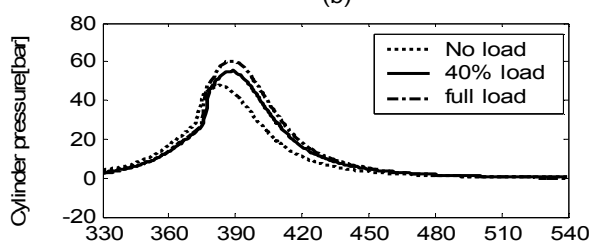

(d)

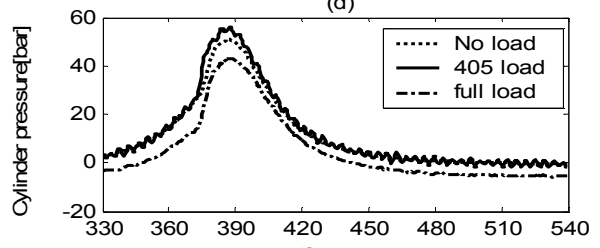

(f)

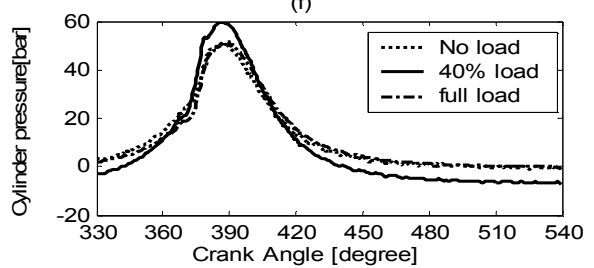

Fig.9. The measured cylinder pressure and reconstructed ones at zero load, $40 \%$ load and full load, (a) measured, (b) Zoom of measured, (c) reconstructed from acoustic signals, (d) Zoom of reconstructed from the acoustic signals, (e) reconstructed from vibration signals, (f) Zoom of reconstructed from vibration signals. 


\section{CONCLUSIONS}

In this paper the reconstruction of in-cylinder pressure using inverse filtering technique is presented. It is shown that reconstructing the in-cylinder pressure from acoustic and vibration measurements has been successfully achieved by the mentioned technique.

Reconstruction of cylinder pressure by inverse filtering technique can be applied for real-time on-board control and misfire detection in multi-cylinder engines, while eliminating the need for in-cylinder pressure transducers.

The reconstructed cylinder pressure from vibration signal at constant speed and different loads is the same as that reconstructed from the acoustic signal at that speed and loads. In other words the reconstructed cylinder pressures from acoustic and vibration signals have the same root mean square error.

To apply reconstruction of cylinder pressure in engine diagnosis and control, it is needed to evaluate a map of FRF's that represents the correlation between engine vibration and acoustics, and combustion pressure over a wide range of engine speeds and loads.

\section{REFERENCES}

1. Zeng, P. and Deenis N. Assanis, "Cylinder Pressure Reconstruction and its Application to Heat Transfer Analysis", SAE paper, 2004-01-0922, (2004).

2. Zeng, P., Robert G. Prucka, Zoran S. Filipi and Dennis N. Assanis, "Reconstructing Cylinder Pressure of a Spark-Ignition Engine for Heat Transfer and Heat Release Analyses", Proceedings of ASME, ICEF 2004-886, (2004).

3. Citron S. J., John E. O'Higgins and Lillian Y. Chen, "Cylinder by Cylinder Engine Pressure and Pressure Torque Waveform Determination Utilizing Speed Fluctuations", SAE 890486, (1989).

4. Brwon, T. S. and W. Stuart Neill, "Determination of Engine Cylinder Pressures from Crankshaft speed Fluctuations", SAE 920463, (1992).

5. Moro, D. and Enrico Corti, "Real Time In-Cylinder Pressure and Torque Estimation in a 6 Cylinders Turbocharged Engine", Online, www.machine.unisa.it/MECAO2/papers/MECAO2_paper01.pdf

6. El-Gamry, M., J. A. Steel, R. L. Reuben and T. L. Fog, "Indirect Measurement of Cylinder Pressure from Diesel Engines using Acoustic Emission", Mechanical Systems and Signal Processing, Accepted 27 September 2004, (2004).

7. McConnell, Kenneth G, Vibration Testing: Theory and Practice, John Willey \& Sons, INC., First edition, New York, (1995).

8. Rao, Singiresu S., Mechanical Vibration, $4^{\text {th }}$ edition, Prentice Hall, New Jersey, (2004). 
9. Ewins, D. J., Modal Testing: theory, practice and application, $2^{\text {nd }}$ edition, Resarch Studies Press LTD., England, (2000).

10. Ziemer R. E., William H. Tranter and D. Ronald Fannin, "Signal and Systems: Continuous and Discrete", $4^{\text {th }}$ edition, Prentice Hall, (1998).

11. SAE J1074 FEB87, "Engine Sound Level Measurement Procedure (A)", SAE HandBook, Volume 3, (1989).

\section{Appendix (A)}

\section{Engine Specifications}

Engine model:

F1L-511

Number of strokes:

4

Bore:

$100 \mathrm{~mm}$

Stroke:

$105 \mathrm{~mm}$

Swept volume:

$825 \mathrm{~cm}^{3}$

Compression ratio:

$17: 1$

Cooling:

Air cooling

Appendix (B)

Calibration Curve of Pressure Transducer

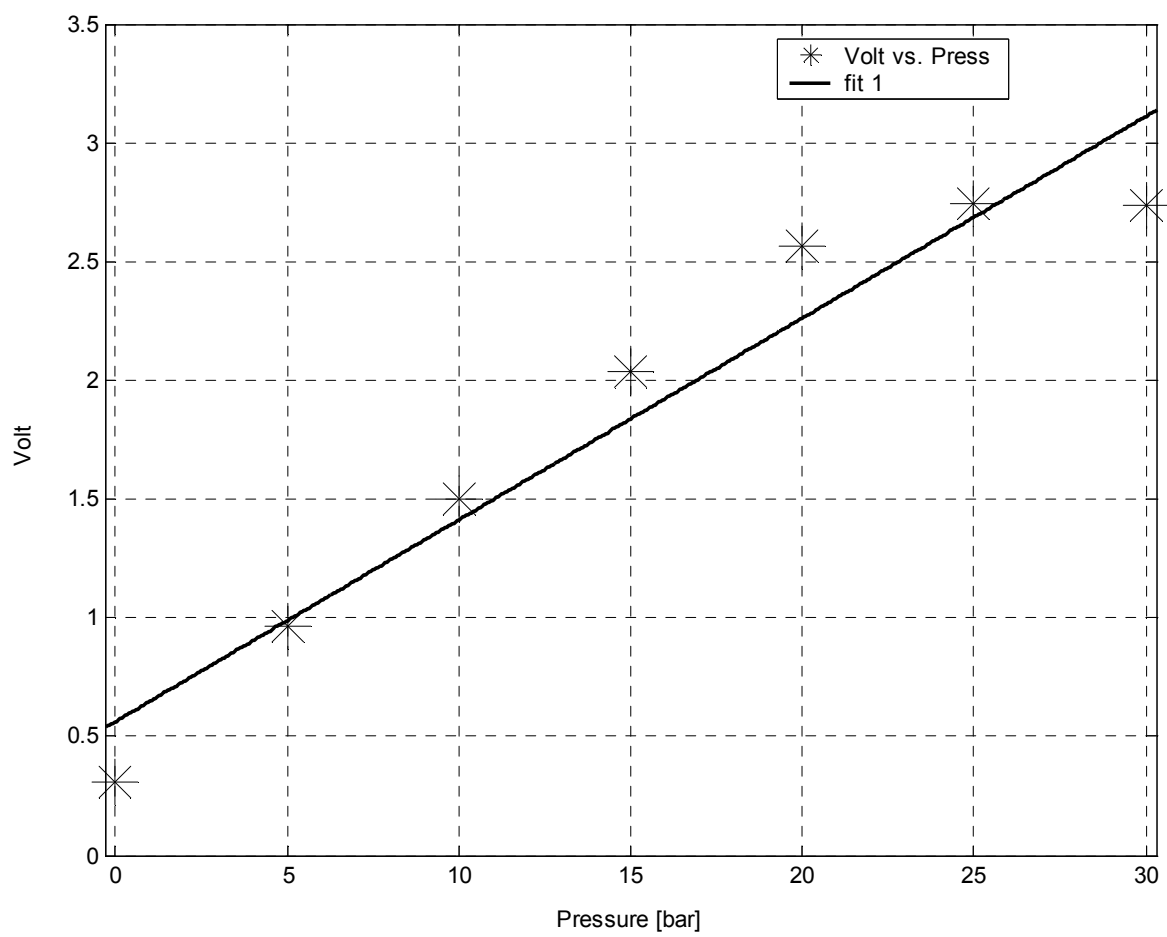

